\section{Science, Logic and Philosophy}

My attention has been directed by Mr. John Bradley of Christ's Hospital, Horsham, to a passage by Prof. J. H. Muirhead ${ }^{1}$, containing the words : "The truth is that what is called a natural law is itself not so much a statement of fact as of a standard or type to which facts have been found more or less to approximate. This is true even in inorganic nature." My statement ${ }^{2}$ that the variation of observations from a mathematical formula is quite unknown to philosophical critics has therefore at least one exception, which I am glad to acknowledge. But much in philosophical works would receive additional force from its recognition; for example, in the later parts of Prof. L. S. Stebbing's "Philosophy and the Physicists". Mr. Bradley directs attention also to a passage in Plato: "I have never been able to find out anything for certain and have had to be content with the probable." Locke said the same thing at greater length, and W. E. Johnson made important constructive contributions to the quantitative theory; so I did not intend to disparage the contributions of philosophers to this side of the question.

My opening passage should have been expressed somewhat differently, and should be read in conjunction with the closing one. Two correspondents have referred to it as a refutation of idealism, but it is only a refutation of a particular form of it. I show in the course of the article that the scientific use of generalization can permit even an idealist to escape from solipsism, and my final conclusion is that there are forms of realism and idealism that are scientifically equally valid. My own preference is for the realist one, but I admit that that is pure prejudice. On the other hand, I am not sufficiently familiar with idealist literature to say whether any actual idealist would accept the form of idealism that I consider tenable.

\section{HAROLD JEFFREYS.}

\section{St. John's College,} Cambridge.

1 "The Elements of Ethics" (1910), pp. 37-38

'NATURE, 141, 672-676, 716-719 (1938).

\section{A Binocular Illusion}

THE interesting binocular illusion described by Prof. Dixon ${ }^{1}$ is usually called the wall-paper experiment in England and Tapetenbilder in Germany. It has frequently been rediscovered-often by children - and I know of a number of people who have found it out for themselves.

Exactly two hundred years ago Robert Smith ${ }^{2}$, afterwards Master of Trinity College, Cambridge, described the illusion of binocularly fusing two candle flames by converging the visual axes on a nearer point. The effect was that of a smaller candle closer to the observer. H. Meyer ${ }^{3}$ in 1842 published a detailed account of the phenomenon as seen in patterned wall-papers. Two years later it was seen by D. Brewster' in wall-papers, carpets, and other patterned objects. He described the curious unreality of the appearance-a semi-transparent object suspended in the air and moving with every movement of the observer. He always claimed to be the original discoverer, and made no reference to Smith or Meyer.

The chief physiological interest of the illusion is that it has seemed to several writers to indicate that the amount of convergence of the eyes necessary to avoid diplopia is an important datum in the visual judgment of distance. It is possible, however, that the illusory closeness of the percept is mainly due to the fused pattern being judged to be at about the known distance from the observer of the fixation point, or of other objects the images of which fall on corresponding points of the two retinas.

R. S. Creed.

New College,

Oxford.

May 4.

1 Dixon, H. H., NATURE, 141, 792 (1938).

"Smith, R., "A Compleat System of Opticks" (Cambridge, 1738), vol. 2, Remarks, p. 86 and Fig. 161.

- Arch. physiol. Heilk., 1, 316-326 (1842).

- Trans. Roy. Soc. Edin., 15, 663-675 (1844); Phil. Mag., 30, 305308 (1847); "The Stereoscope" (London, 1856), Chap. vi.

\section{Ounce Molecular Weight of a Gas}

ThE useful equivalence, gm. per litre $=$ oz. per cub. ft. (approx.), as a practical connecting link between metric and British weight-volume relation. ships, referred to by Dr. H. D. H. Drane in Nature of April 30 (p. 791) is well known to industrial chemists and engineers, and appears in Woodward's "Logs and Tables for Chemists" (1917), p. 62.

The much older expression of the same equivalence, pounds per cub. ft. $\times 16=\mathrm{kgm}$. per cub. metre has appeared in various engineers' handbooks for more than twenty-five years (for example, Frye's "Civil Engineers' Pocket-Book" (1912), p. 89). Easily remembered equivalents of this kind constitute one of the first lessons learned by a laboratory worker when he goes into industry.

In the case of gases, where we generally deal with large volumes, Lunge's simple calculation ("Alkali Maker's Handbook" (1891) p. 26) based on the same equivalence of gram and ounce molecular weights, is most useful. The molecular weight of a gas divided by 4 gives the approximate weight in cwt. of 10,000 cubic feet. This may also be applied to mixtures of gases. For example, the average molecular weight of dry air, calculated as one fifth oxygen and four fifths nitrogen, is $28 \cdot 8$, and $\frac{28 \cdot 8}{4}=7 \cdot 2$ cwt. Fer 10,000 cub. ft. The precise figure at N.T.P. is $7 \cdot 206$ cwt.

The volume of an ounce molecular weight of oxygen as visualized approximately by Dr. Drane is 22.5 cub. ft. weighing approximately $2 \mathrm{lb}$. The actual weight at N.T.P. is $2.008 \mathrm{lb}$. and calculated by Lunge's method is $2 \cdot 016 \mathrm{lb}$.

I entirely agree with Dr. Drane that notes of such relationships between metric and British units might well appear in the text-books.

The Orchard,

James Strachax.

$$
\begin{gathered}
\text { Hook Green, } \\
\text { Meopham, } \\
\text { Kent. } \\
\text { April 30. }
\end{gathered}
$$

THE fact that the molecular weight of a gas or vapour in ounces occupies $22.4 \mathrm{cub}$. ft. at S.T.P. seems to have been pointed out first by Prof. J. W. Richards in an article on "Some Abridgments in Chemical Calculations", published in the Journal of the Franklin Institute, 152, 109 (1901). It is quoted 